\title{
Sabarabuçu: Um jogo digital educacional, cultural e ambiental para o município histórico de Sabará
}

\author{
Pedro A. Lourenço, Lucas P. Leal, Estela M. P. Diaz, Carlos A. Silva

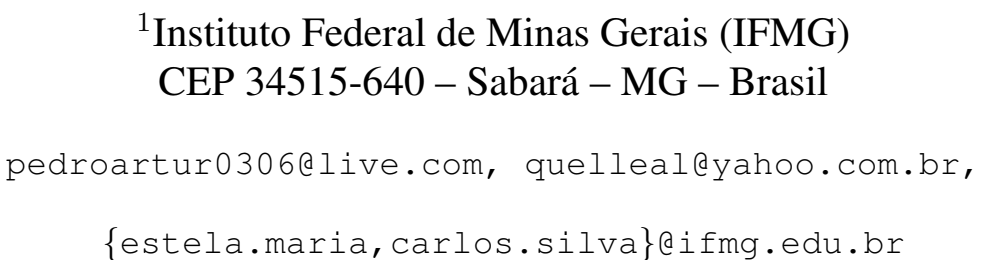

\begin{abstract}
In this paper we present the development of a digital game about an important historical city of Minas Gerais. The game addresses education, cultural dissemination, preservation of historical monuments, environmental education and social inclusion. Open-source software was used and the arts and sounds has done by authors themselves.
\end{abstract}

Resumo. Neste artigo apresentamos o desenvolvimento de um jogo digital cujo enredo é contextualizado em um município histórico de Minas Gerais e aborda temáticas ligadas a educação, disseminação cultural, preservação de monumentos históricos, educação ambiental, inclusão social, além de ser caracterizado pela utilização de softwares open-source e criação de arte e sons dos próprios autores.

\section{Introdução}

O mercado de jogos vem se expandindo ao longo dos últimos anos. De acordo com a [Newzoo 2015], empresa de consultoria e pesquisa de mercado especializada em games, o mercado global movimentou mais de $\mathrm{R} \$ 270$ bilhões no ano de 2015 e tem previsão para ultrapassar R\$ 320 bilhões em 2017. No contexto nacional, o mercado de games movimenta mais de R \$ 40 milhões, fazendo com que os jogos eletrônicos deixassem de ser apenas passatempo para se tornarem alternativas lucrativas de negócios. Apesar destes números, a realidade é que o Brasil consome um grande volume de jogos, porém produz pouco.

Neste trabalho buscamos por meio de um jogo ilustrar como enredo parte dos potenciais turísticos e culturais do município histórico de Sabará em Minas Gerais. Além disso, o jogo tem como propósito ser um agente educacional propiciando a difusão de elementos educacionais como a consciência ambiental; estimular a reflexão sobre a diversidade de etnias e contextualizar e conscientizar sobre o transtorno do espectro autista. Inicialmente a expectativa da aplicação do jogo é em um ambiente educacional, visto os benefícios proporcionados pelo uso da tecnologia no ensino de disciplinas.

Apesar do jogo desenvolvido ter por objetivo a criação de uma metodologia educacional por meio da gameficação abordando temáticas sociais e culturais, o cenário atual de games é promissor, ampliando a possibilidade do resultado desta pesquisa para fins comerciais. 


\section{Metodologia e Ferramentas Computacionais}

Para o acompanhamento do desenvolvimento do jogo foi utilizado o Game Design Document (GDD), responsável pela documentação de todas as informações necessárias para projeção das fases, o enredo do jogo, a caracterização dos personagens, as movimentações, o balanceamento entre outros. A plataforma de desenvolvimento utilizada foi o Game Maker Studio que se trata de uma engine gratuita possibilitando o desenvolvimento do jogo em dimensão até 2,5D utilizando técnicas de Parallax. Inicialmente foram feitos os esboços do jogo, os quais foram transferidos para o computador via mesa digitalizadora, a fim de preservar a originalidade dos traços, sendo que a pintura da arte do jogo foi utilizado o InskScape. Por meio da arte dos autores deste trabalho foram esboçados e digitalizados vários monumentos históricos da cidade, além de caracterizar por meio de sprites, a fruta jabuticaba, que representa um patrimônio gastronômico do município. Posteriormente foi produzida a trilha sonora, a qual foi montada e composta pelos autores. Utilizou-se uma flauta doce com timbre soprano e os demais arranjos foram digitalizados. A preocupação com o enfoque educacional é primordial ao desenvolvimento do jogo. Utilizamos os conceitos de Diferenciação Progressiva e Reconciliação Integrativa conforme apresentados em [Ausubel 2010] e [Mendes 2011]. Estes dois processos auxiliam na aprendizagem satisfatória do aluno/aprendiz no jogo. Na Diferenciação Progressiva, os novos conhecimentos devem ser apresentados de forma gradual em uma ordem crescente de especificidade. Durante o jogo é necessário responder quizzes e coletar pedaços de mapas que remetem a totens contextualizando o patrimônio histórico da cidade, adquirindo conhecimento cultural a medida em que se avança no jogo. Na Reconciliação Integrativa, a preocupação está em elucidar eventuais semelhanças, diferenças e contradições de modo que o estudante possa fazer novas conexões de conhecimento. No game esta característica é visível a partir do conhecimento previamente adquirido na leitura dos totens e coleta de itens, os quais são utilizados para coleta de novas partes dos mapas. Além disso, durante as etapas subsequentes do jogo, novas habilidades são adquiridas, como por exemplo o trabalho em equipe e resolução de conflitos.

\section{O Jogo Sabarabuçu}

Inspirado no jogo "O Mundo de Jequi”, Sabarabuçu retrata uma ambientação local, porém caracterizando sua principal vocação que é o turismo, seja pela representatividade das inúmeras igrejas históricas, ou pela riqueza ambiental ou pela tradicional gastronomia. O nome Sabarabuçu é uma abreviação da palavra tupi tesáberabusu que significa "grandes olhos brilhantes", se referindo às pepitas de ouro que foram encontradas na região e este foi o nome da cidade no princípio de sua história. Estão presentes no jogo as jabuticabas, consideradas na cidade como "Ouro Negro", além das famosas igrejas barrocas como a Igreja Nossa Senhora do Ó e Igreja Nossa Senhora do Carmo. O jogo desenvolvido tem por objetivo disseminar a cultura local e estimular a educação social e ambiental. Inicialmente o público-alvo do jogo seriam estudantes de escolas públicas da cidade, podendo conciliar as atividades do jogo com conteúdo de disciplinas da escola, como história. O jogo estará disponível em um plataforma web, na qual existirá um formulário de satisfação e quizzes sobre o jogo. A partir destas informações, serão feitas análises estatísticas para verificar o desempenho e o aprendizado dos participantes. 


\subsection{Abordagem Educacional, Cultural e Ambiental}

A cidade de Sabará foi o primeiro povoado de Minas Gerais e uma das primeiras áreas onde se encontrou ouro no Brasil, além de apresentar em sua arquitetura o primeiro barroco brasileiro. O município pertence à famosa rota da Estrada Real (ER), sendo esta a maior rota turística do país passando pelos estados de São Paulo, Rio de Janeiro e Minas Gerais. Alguns dos importantes locais históricos e turísticos da cidade, como a Igreja do Ó, considerada um dos cartões postais da cidade, foi retratada no jogo. Além do importante contexto histórico da cidade no cenário regional e nacional presentes no jogo, o desenvolvimento deste trabalho prevê o estímulo de ações de consciência ambiental e cidadania. A aplicação do jogo como material didático educacional está em fase de conversação com escolas da rede pública da cidade.

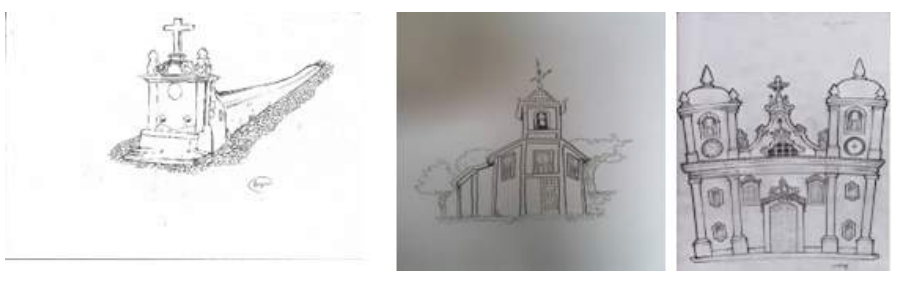

Figura 1. Primeiros Sketches dos pontos turísticos de Sabará, Chafariz do Kaquende, Igreja Nossa Senhora do Ó, Igreja Nossa Senhora do Carmo da esquerda para a direita.

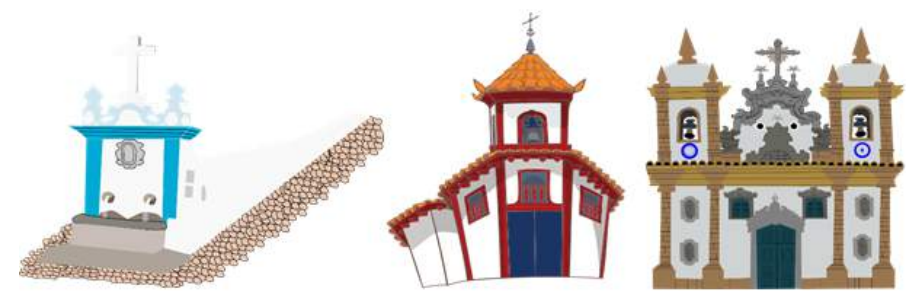

Figura 2. Sketches dos pontos turísticos de Sabará, Chafariz do Kaquende, Igreja Nossa Senhora do Ó, Igreja Nossa Senhora do Carmo da esquerda para a direita com pintura digital aplicada.

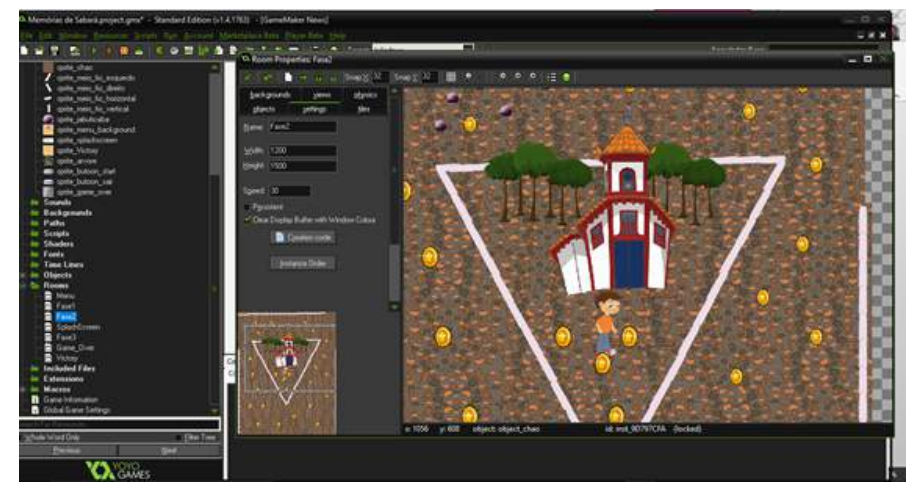

Figura 3. Personagem principal na fase do Largo do Ó. 


\subsection{Caracterização dos Personagens}

Os personagens foram criados com características específicas e contemplam os temas de diversidade étnico-racial e transtorno do espectro autista (TEA). Levou-se em consideração as etnias indígenas e africanas pela sua relevância histórica no contexto nacional e em específico da cidade de Sabará. Além disso, o ambiente do jogo se passa no imaginário do personagem principal que possui a característica do autismo, tema este de suma importância quando se trata da inclusão social, especialmente no meio educacional.

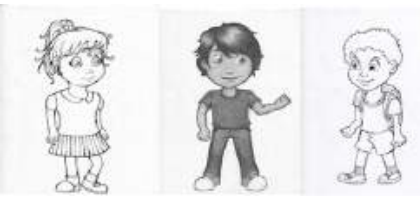

Figura 4. Primeiros sketches dos personagens, da esquerda para a direita Yaya (Yasmim), Kadu (Carlos Eduardo), Dan (Daniel).

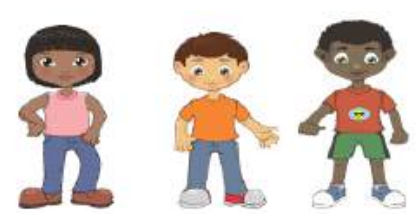

Figura 5. Segundo sketch e final dos personagens já com a pintura digital, seguindo da esquerda para a direita Yasmin (etnia indígena), Carlos Eduardo (Autista) e Daniel (etnia africana).

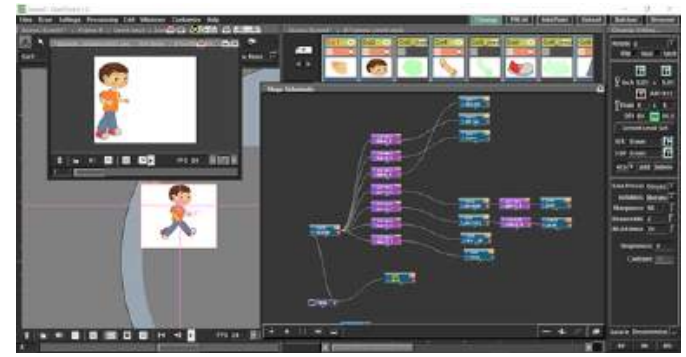

Figura 6. Animação do personagem no Open Toonz.

\section{Conclusão}

Por meio do jogo Sabarabuçu, foram inseridas as temáticas de cultura afro-brasileira, indígena, transtorno do espectro autista e educação ambiental. Espera-se com este jogo promover um turismo virtual da cidade histórica mineira de Sabará. Além disso, o jogo poderá ser utilizado como ferramenta de auxílio no processo de ensino e aprendizagem nas escolas de ensino básico.

\section{Referências}

Ausubel, D. (2010). The acquisition and retention of knowledge: A cognitive view. Dordrecht.

Mendes, T. G. (2011). Jogos digitais como objetos de aprendizagem: Apontamentos para uma metodologia de desenvolvimento. In SBGames.

Newzoo (2015). Global games market will grow 9.4\% to US\$91.5bn in 2015. 